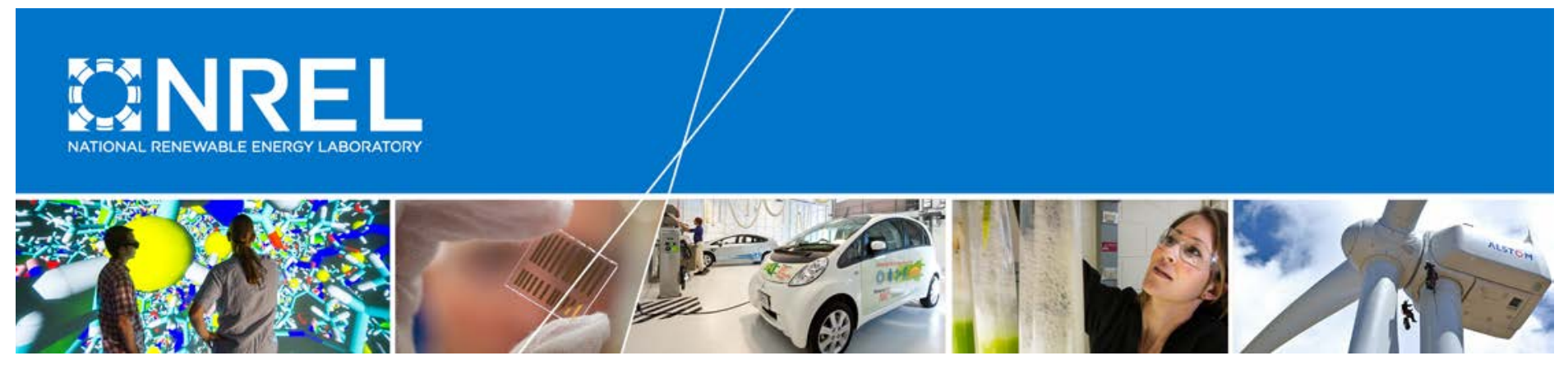

\title{
Residential Advanced Photovoltaic Inverter Pilot Study Results for Select Distribution Secondaries in Hawai'i
}

\section{Preprint}

Peter Gotseff, Nick Wunder, and Andy Hoke National Renewable Energy Laboratory

Earle Ifuku and Reid Ueda Hawaiian Electric Company

Presented at the 2018 World Conference on Photovoltaic Energy Conversion (WPEC-7)

Waikoloa, Hawaii

June 10-15, 2018

(C) 2018 IEEE. Personal use of this material is permitted. Permission from IEEE must be obtained for all other uses, in any current or future media, including reprinting/republishing this material for advertising or promotional purposes, creating new collective works, for resale or redistribution to servers or lists, or reuse of any copyrighted component of this work in other works.

\section{Suggested Citation}

Gotseff, Peter, Nick Wunder, Andy Hike, and Earle Ifuku. 2018. "Residential Advanced Photovoltaic Inverter Pilot Study Results for Select Distribution Secondaries in Hawai'i: Preprint." Golden, CO: National Renewable Energy Laboratory. NREL/CP-5D00-71587. https://www.nrel.gov/docs/fy18osti/71587.pdf

NREL is a national laboratory of the U.S. Department of Energy Office of Energy Efficiency \& Renewable Energy Operated by the Alliance for Sustainable Energy, LLC

This report is available at no cost from the National Renewable Energy Laboratory (NREL) at www.nrel.gov/publications.

\section{Conference Paper}

NREL/CP-5D00-71587

August 2018

Contract No. DE-AC36-08GO28308 


\section{NOTICE}

This work was authored in part by the National Renewable Energy Laboratory, operated by Alliance for Sustainable Energy, LLC, for the U.S. Department of Energy (DOE) under Contract No. DE-AC36-08GO28308. Funding provided by the Hawaiian Electric Company and the U.S. Department of Energy Office of Energy Efficiency and Renewable Energy. The views expressed in the article do not necessarily represent the views of the DOE or the U.S. Government. The U.S. Government retains and the publisher, by accepting the article for publication, acknowledges that the U.S. Government retains a nonexclusive, paid-up, irrevocable, worldwide license to publish or reproduce the published form of this work, or allow others to do so, for U.S. Government purposes.

This report is available at no cost from the National Renewable Energy Laboratory (NREL) at www.nrel.gov/publications.

U.S. Department of Energy (DOE) reports produced after 1991 and a growing number of pre-1991 documents are available free via www.OSTI.gov.

Cover Photos by Dennis Schroeder: (left to right) NREL 26173, NREL 18302, NREL 19758, NREL 29642, NREL 19795.

NREL prints on paper that contains recycled content. 
Residential Advanced Photovoltaic Inverter Pilot Study Results for Select Distribution Secondaries in Hawai ‘ $i$

\author{
Peter Gotseff ${ }^{1}$, Nick Wunder ${ }^{1}$, Andy Hoke ${ }^{1}$, Earle Ifuku ${ }^{2}$, and Reid Ueda ${ }^{2}$ \\ ${ }^{1}$ National Renewable Energy Laboratory, Golden, CO, 80401, USA \\ ${ }^{2}$ Hawaiian Electric Company, Honolulu, HI, 96813, USA
}

\begin{abstract}
Penetration levels of residential rooftop solar photovoltaic (PV) generation on the Hawaiian island of $\mathrm{O}^{\prime}$ ahu have increased significantly in recent years, with many circuits now at the limits of their PV hosting capacity. NREL and Hawaiian Electric have used this opportunity to deploy advanced inverters at new customer installations that would not otherwise have been approved, as a pilot study to gain first-hand operational field data and experience on the impact of inverter-based grid support functions. At each customer location, the deployed advanced inverters were remotely controlled and monitored. Additionally, customer AMI (smart meter) and secondary distribution transformer data was also available for the analysis. The analysis focused on quantifying the customer behind-the-meter voltage rise due to $\mathrm{PV}$ production, determining the customer voltage rise with advanced inverters in unity power factor as well as advanced grid support function modes, and estimating the curtailment when inverters have Volt-VAR and Volt-Watt enabled. The results show that: 1) Behind-the-meter voltage rise is often not negligible. 2) An inverter's operating point on a Volt-VAR/Volt-Watt curve depends strongly on the design of the secondary system on which it is installed. 3) The mitigation of voltage rise on the secondary system using Volt-VAR may not be effective if only a small proportion of inverters have grid support enabled, or if the reactance/resistance $(\mathrm{X} / \mathrm{R})$ ratio of the grid is low. 4) Volt-Watt curtailment can be estimated using co-located irradiance sensors but there may be opportunities to estimate it using inverter internal electrical measurements. 5) Estimated curtailment is very low for the locations analyzed to date.
\end{abstract}

Keywords-Inverters, Volt-var control, Volt-watt control, Photovoltaics

\section{INTRODUCTION}

It is well known that high penetrations of solar photovoltaic systems (PV) can adversely impact distribution system operations and power quality, and it is an emerging interconnection requirement that advanced inverters provide grid support services (Volt-VAR, Volt-Watt, frequency-Watt, voltage/frequency ride-through) to mitigate these impacts and increase the cumulative benefits from distributed PV generation. In fact, the current version of Hawaiian Electric's Rule $14 \mathrm{H}$ interconnection standard, as approved by the Hawai' $\mathrm{i}$ Public Utility Commission, requires activation of ride-through,

This work was authored in part by Alliance for Sustainable Energy, LLC, the manager and operator of the National Renewable Energy Laboratory for the U.S. Department of Energy (DOE) under Contract No. DE-AC36-08GO28308. Funding provided by Hawaiian Electric and by the U.S. Department of Energy Office of Energy Efficiency and Renewable Energy. The views expressed in the article do not necessarily represent the views of the DOE or the U.S.
Volt-VAR control, and frequency-Watt control for all distributed inverters [1]. Volt-Watt control is permitted to be enabled on an as-needed basis. The California Public Utility Commission (CPUC) is also currently implementing advanced inverter functionality including Volt-VAR and Volt-Watt into Rule 21 [2]. In addition, the underlying standard, IEEE 1547, was recently rewritten to support implementation of these functions [3].

However, most work that has been done to address the implementation of the function settings and the impact these functions will have on grid performance has been through laboratory testing [4]-[6] and computer modeling studies [7], [8]. Most computer modeling studies evaluate the effect of advanced inverter functions as if they were connected at the primary voltage level of the distribution system or with a homogeneous generic representation of the secondary voltage lines to the final customer location or Point of Common Coupling (PCC or electric meter) and PV generator. However, in practice, customer secondary design is very diverse, especially in older non-homogeneous residential neighborhoods.

More recent modeling efforts by NREL and HECO have focused on distribution circuit analysis from the primary distribution voltage level complete to the distribution transformer and finally to the customer premises using representative sampled secondaries [8]. This study found significant benefits of Volt-VAR and Volt-Watt control in terms of power quality, with minimal impact on PV energy production.

However, these secondary models and expected Volt-VAR effectiveness should be consistent with field measurements. To this end Hawaiian Electric, in collaboration with the National Renewable Energy Laboratory (NREL), extended an offer to some number of queued net energy metering (NEM) residential PV customers whose systems were not able to be installed due to expected issues with voltage or thermal limits. Note that inverter grid support functions may address voltage issues but are not expected to address thermal issues. The offer included an option to install advanced inverters with Volt-VAR/VoltWatt grid support functions activated with allowances that the

Government. The U.S. Government retains and the publisher, by accepting the article for publication, acknowledges that the U.S. Government retains a nonexclusive, paid-up, irrevocable, worldwide license to publish or reproduce the published form of this work, or allow others to do so, for U.S. Government purposes. 
data be used for research. This paper describes several initial outcomes of that field pilot study, which is ongoing at the time of publication. This pilot study hopes to build on the results of other residential advanced inverter pilots [9], [10], by evaluating both utility-side impacts and customer-side impacts.

\section{FIELD DEPLOYMENT AND TeST CASES}

At the time of this writing, the pilot was made up of 15 separate customer locations representing $12240 \mathrm{~V}$ secondary circuits. Typically, the secondary circuit is a radial design where a main conductor is fed from the distribution transformer and each house is "tapped" off the main secondary conductor. Of the new controllable inverters in this study, there were 11 string inverters and four microinverter arrays. In all cases there were existing "legacy" PV systems (i.e., not capable of providing voltage support functions) already connected on the secondary circuits.

The field data for the pilot study consisted of the inverter, pilot customer and distribution transformer electrical parameters collected at intervals that ranged from 5 minutes to less than one minute (Fig. 1). Additional hardware included plane of array (POA) irradiance sensors located at two PV arrays.

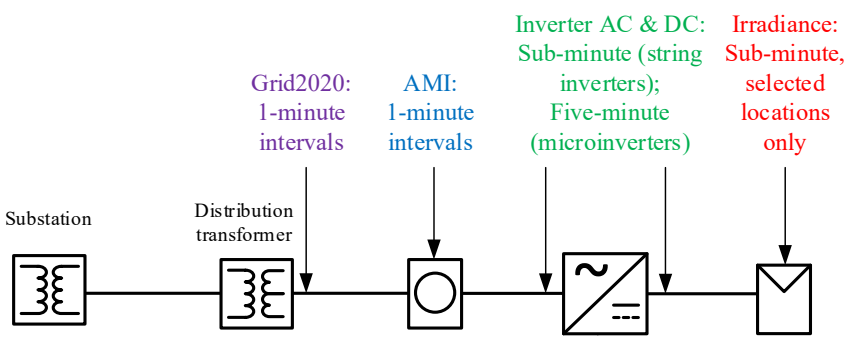

Fig. 1. Data collection locations. Microinverter data was recorded at each individual microinverter in each PV array.

To gauge advanced inverter effectiveness, each of the inverters were programmed, for a period of time anywhere from three days to four weeks, with different combinations of fixed power factor and the Volt-VAR and Volt-Watt curves shown in Fig. 2. The curves selected were based on those currently being used or proposed in Hawai' $i$ and California. Results presented below focus on test cases using the HECO Volt-VAR and VoltWatt curves; results using other curves will be presented in future work.
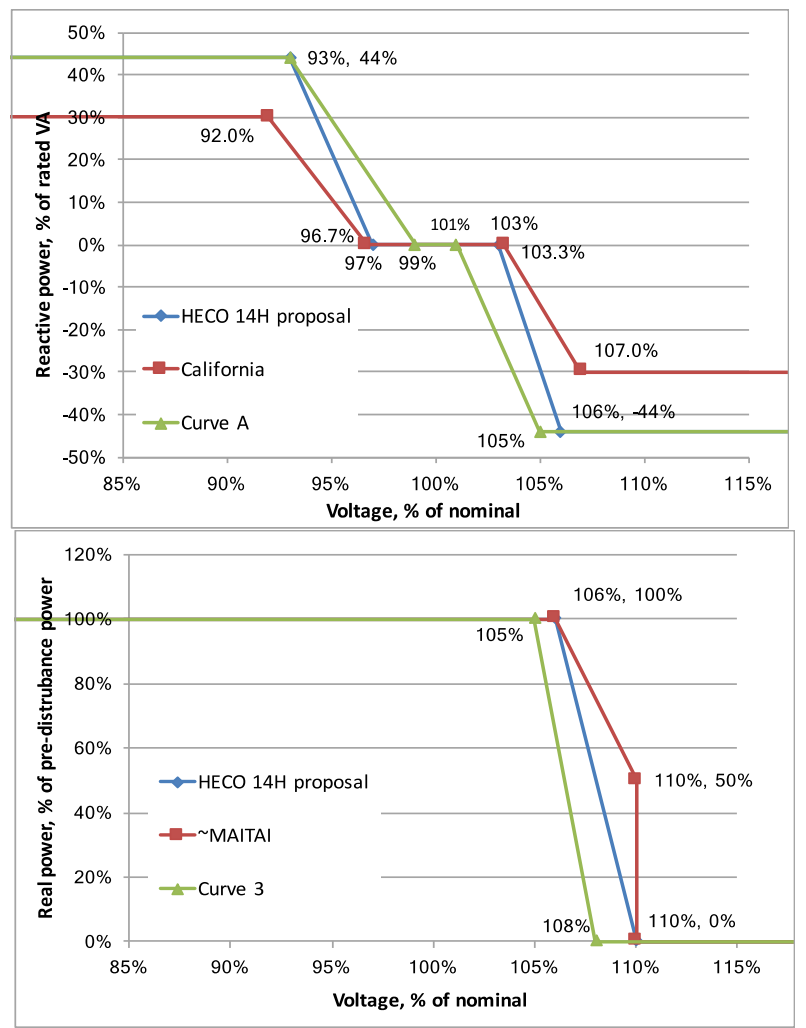

Fig. 2. Volt-VAR curves (top) and Volt-Watt curves (bottom) used in the pilot. The MAITAI curve was produced based on guidance from the Manufacturing Alliance of Inverters Technical Assessment of Integration Issues (MAITAI), as described in [4].

\section{RESULTS}

\section{A. Behind-the-Meter Voltage Rise}

The root-mean-square (RMS) voltage difference between the inverter and customer meter was obtained for all string and microinverters in the pilot. This is also known as the behindthe-meter voltage rise $\left(\Delta V_{\mathrm{btm}}\right)$ and is dictated by the impedance of the wiring on the customer's premises $\left(Z_{\mathrm{btm}}\right)$ and the current flowing in that wiring, as shown in Fig. 3 for the simple case where the effect of load local current on $\Delta V_{\mathrm{btm}}$ is small enough be neglected. Behind-the-meter voltage rise is typically not modeled even in very detailed computer simulations of distribution feeders with distributed PV systems, but its impact can be important, especially considering that Volt-VAR and Volt-Watt output changes substantially over a range as small as 0.01 pu voltage.

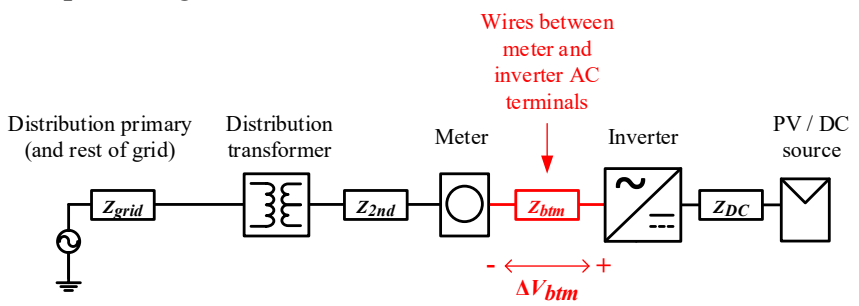

Fig. 3. Behind-the-meter voltage rise is one of several sources of voltage change and loss in a PV system. 
String inverters are often - but not always - installed very near the meter and hence $\Delta V_{\mathrm{btm}}$ is expected to be negligible in many cases. Microinverters are installed under the PV modules and hence have longer wire runs and are expected to experience greater voltage rise.

For this test, the inverters were set to unity power factor for three days. Fig. 4. shows the voltage rise from the customer meter to the inverter plotted against the inverter current, as well as the fitted linear regression (light blue), for string inverters. As expected, the string inverters experience a relatively small voltage rise ranging from $0.002 \mathrm{pu}$ to $0.007 \mathrm{pu}$ at full power ( 0.5 to $1.7 \mathrm{~V}$ for a $240 \mathrm{~V}$ service).

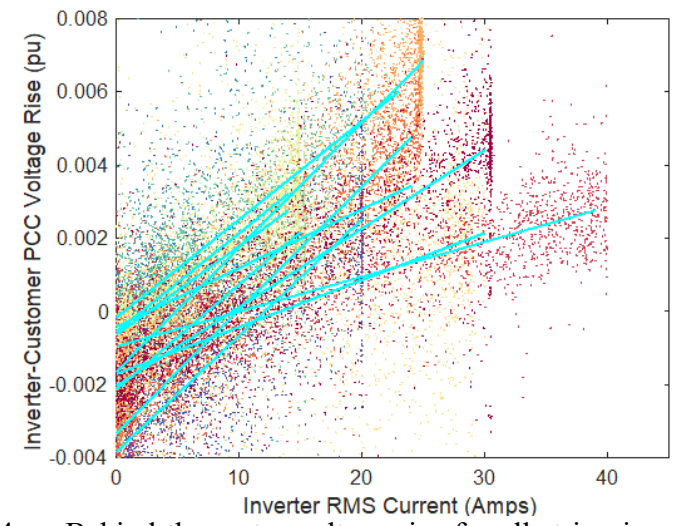

Fig. 4. Behind-the-meter voltage rise for all string inverters in the pilot

Microinverters have shown higher voltage rise, on the order of $0.005 \mathrm{pu}$ to $0.025 \mathrm{pu}(1.4 \mathrm{~V}$ to $6 \mathrm{~V}$ for a $240 \mathrm{~V}$ service) at full power as shown in Fig. 5 . The negative voltage rise offsets seen in the figures are attributed to voltage drop due to customer loads, inaccuracy in the inverter measurements, and timestamp mismatch between the inverter and AMI (advanced metering infrastructure, or smart meter) measurements.

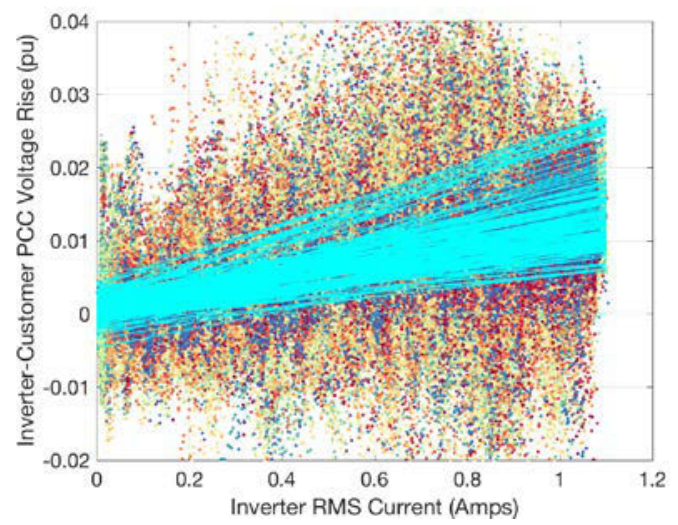

Fig. 5. Behind-the-meter voltage rise for all microinverters in the pilot

\section{B. PV Power-Voltage Relationships}

The RMS voltage difference from the distribution transformer to the inverter will drive the Volt-VAR and Volt-
Watt functions and is dictated by the utility's secondary system, behind-the-meter circuitry, and loads and PV generation on that system. Fig 6 shows a case of high voltage rise $(\sim 0.06 \mathrm{pu})$ from the transformer to one customer's inverter in an overhead secondary system with 15 customers, $25 \mathrm{~kW}$ of legacy PV at unity or fixed power factor, and $9.8 \mathrm{~kW}$ of new controllable advanced inverters. The blue dots show the RMS voltage rise dependency on PV power production with the controllable inverters operating at unity power factor. The red dots show the voltage rise for the inverters operating per HECO curve $14 \mathrm{H}$ Volt-VAR/Volt-Watt (per Fig 2). The linear regression is plotted for each mode.

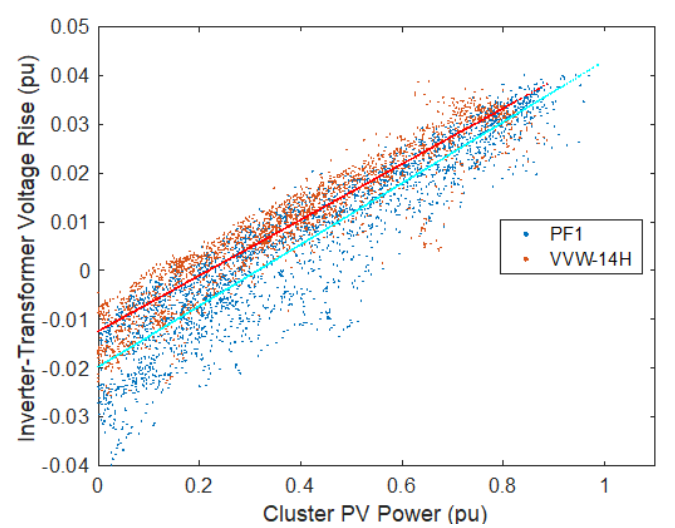

Fig. 6. Transformer-to-inverter voltage rise dependency on PV power in an overhead system for two inverter operating modes

Fig. 7 shows the much smaller voltage rise $(\sim 0.012 \mathrm{pu})$ from the transformer to one customer PCC in an underground secondary system with 7 customers, $32 \mathrm{~kW}$ of legacy PV at unity or fixed power factor and $22 \mathrm{~kW}$ of new, controllable, advanced inverters. In this case, because the absolute voltage at the customer PCC never went above $1.03 \mathrm{pu}$, the VoltVAR/Volt-Watt function, even though active, did not cause the inverters to consume VARs. This location was more typical of most of the customers in the pilot in that the voltages were rarely high, and thus the impacts of Volt-VAR and Volt-Watt on PV energy production were negligible.

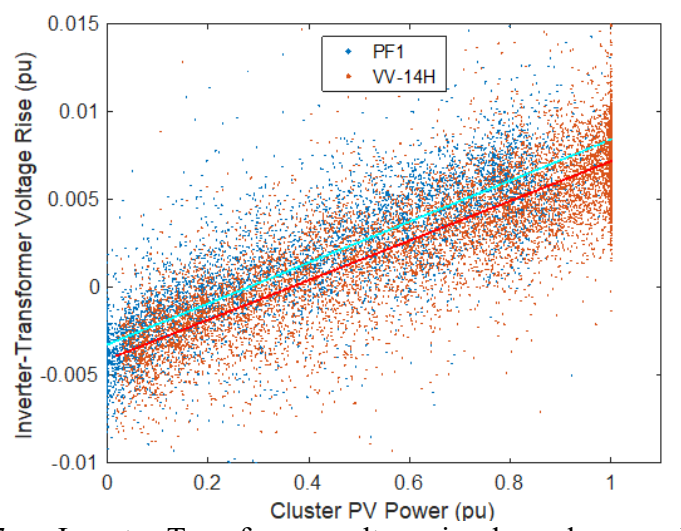

Fig. 7. Inverter-Transformer voltage rise dependency on PV power in an underground system for two inverter operating modes 


\section{Curtailment Estimates}

Despite the fact that the pilot customers were preselected based on expected problematic secondary locations, customer voltages were rarely high enough anywhere in the pilot study for Volt-Watt curtailment to be activated (i.e. $>1.06 \mathrm{pu}$ ) for more than a few minutes in any one day. However, the HECO Volt-VAR and Volt-Watt curves were active when a distribution primary high voltage event occurred for three days on one feeder, as seen in Fig. 8. The calculated curtailment during the high-voltage period is shown in Fig. 9, where dark blue dots are measured power at a given irradiance, light blue dots are determined to be curtailed values and orange dots are estimated power without curtailment. Total energy over these three days was $74.46 \mathrm{kWh}$. Total estimated energy without curtailment (e.g., pf 1.0 without Volt-Watt) would have been $75.69 \mathrm{kWh}$. The estimated curtailment is then $1.23 \mathrm{kWh}$, or $1.6 \%$ of the energy produced during the three-day high voltage period. Figure 10 shows a similar analysis for a three-day period when the voltage was in its typical range for this location. During this period, the actual energy produced was $69.19 \mathrm{kWh}$, and the estimated energy that could have been produced without Volt-VAR and Volt-Watt active was 69.22 $\mathrm{kWh}$, yielding an estimated curtailment of $0.02 \mathrm{kWh}$, or $0.04 \%$. Thus the overall impact of Volt-VAR and Volt-Watt on PV energy production for this customer is negligible. This illustrates one of the key use-cases for Volt-Watt control, where the overall impact on the customer is small, but the function serves as safety-valve to minimize overvoltage during occasional voltage deviations. In this case the secondary has many other PV systems operating at unity power factor without Volt-VAR and Volt-Watt, so the impact of Volt-VAR and VoltWatt in mitigating high voltages is small. Future work will use computer simulations to estimate the improvement in effectiveness if all inverters on the secondary were performing Volt-VAR and Volt-Watt.

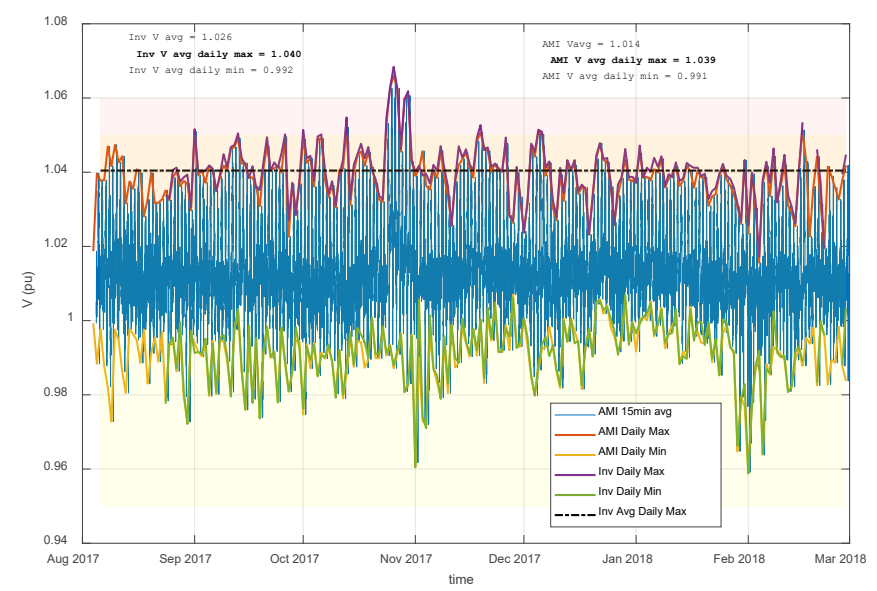

Fig. 8. Meter (AMI) and inverter (Inv) voltages at second-highestvoltage customer, showing high-voltage condition in late October due to a feeder primary configuration change.
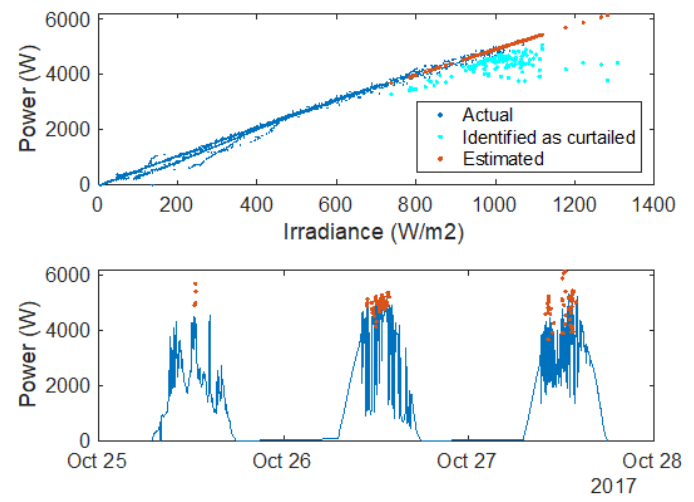

Fig. 9. Curtailment estimates for a PV system with Volt-VAR and Volt-Watt activated during a three-day period where voltage was unusually high due to a temporary feeder configuration change.
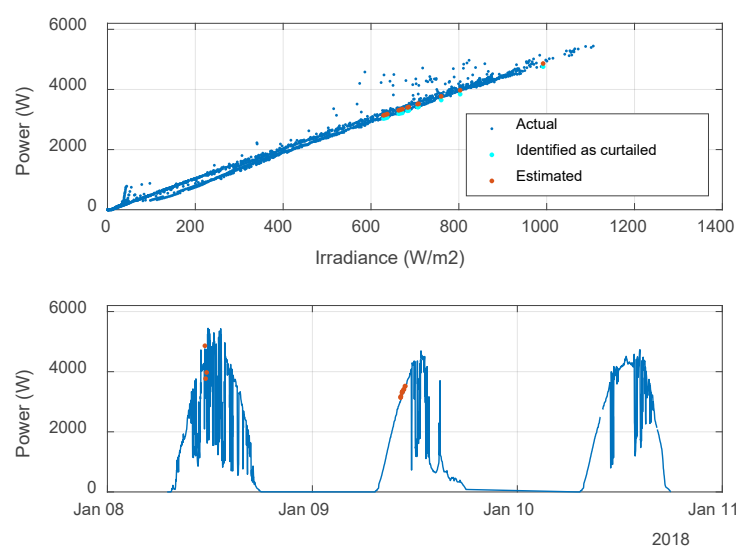

Fig. 10. Curtailment estimates for a PV system with Volt-VAR and Volt-Watt activated during a typical three-day period.

Figure 11 shows inverter active power and reactive power, $\mathrm{AC}$ inverter voltage, and irradiance at the same location as in Figs. 8-10 for a typical day (feeder primary in normal configuration). Note the high correlation between irradiance and voltage: PV output is clearly driving voltage magnitude. Also note that when irradiance reaches (and exceeds) the nominal peak irradiance of $1000 \mathrm{~W} / \mathrm{m}^{2}$, the voltage peaks below $1.06 \mathrm{pu}$, so Volt-Watt is not curtailing power. While the voltage is above $1.03 \mathrm{pu}$, the inverter absorbs reactive power as specified by the HECO Rule $14 \mathrm{H}$ Volt-VAR curve. This results in minimal impact on PV energy production as the inverter still produces about $3.8 \mathrm{~kW}$ (its rated power) even while sinking VARs. This customer had a relatively low ratio of peak PV array power to inverter rated power (DC:AC ratio) at 1.0; future work will examine the effect of adding additional PV panels to bring the DC:AC ratio up to a more typical value in the 1.1-1.3 range. The relatively high voltage at this location is largely due to the long shared overhead secondary conductors with multiple PV systems connected. Because the impedance of the conductors (largely resistive) is large compared to that of the distribution transformer (largely reactive), the grid $\mathrm{X} / \mathrm{R}$ ratio 


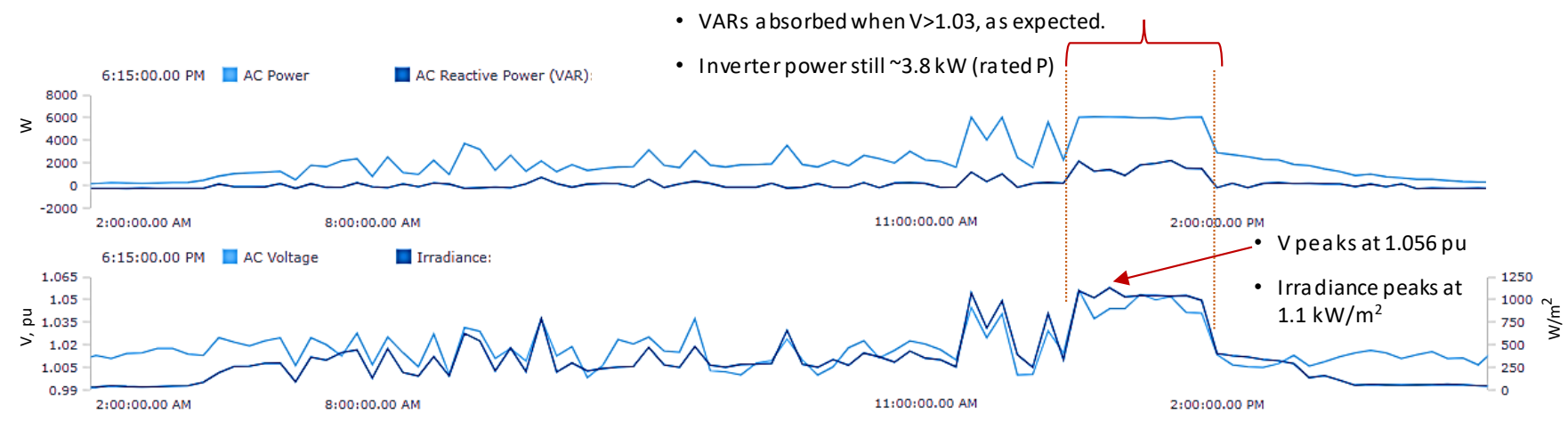

Fig. 11. Inverter power, inverter reactive power, inverter AC voltage, and irradiance over one day for the second-highest voltage customer.

seen by the inverter is low, and VAR absorption can only reduce voltage to a certain degree. This will be examined further in future publications.

The customer analyzed in Figs. 8-11 is the second-highestvoltage location in the pilot, so is expected to represent a near worst-case curtailment condition. This location has a string inverter, and as seen in Fig. 8, behind-the-meter voltage rise is small (maximum AMI voltage and maximum inverter voltage are very similar). The highest voltage location was not yet equipped with an irradiance sensor, so curtailment was not quantified, but will be in ongoing work. Behind-the-meter voltage rise is a significant factor in the highest-voltage location, as seen in Fig. 12.

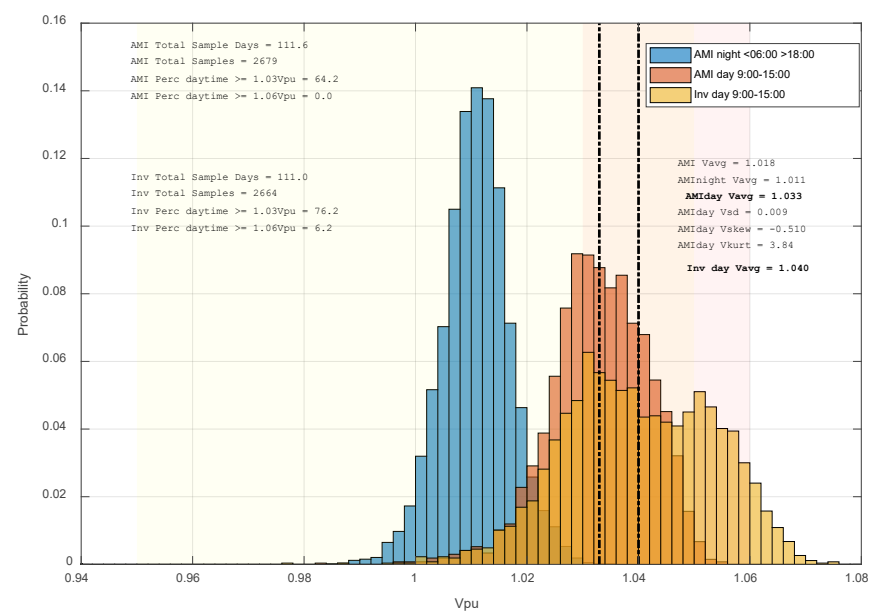

Fig. 12. Histograms of nighttime AMI voltages (blue), daytime AMI voltages (orange), and daytime inverter voltages (yellow) at the highest voltage location in the study. Each histogram is semitransparent to allow visibility of the others.

In Fig. 13, inverter active power, reactive power, and voltage are plotted over a typical day for a more typical location, where the secondary is stronger (lower impedance). In this location there is minimal correlation between voltage and PV output despite the many PV systems on the secondary. Voltage rarely exceeds $1.03 \mathrm{pu}$, so Volt-VAR rarely absorbs VARs, Volt-Watt never curtails active power, and the impact on PV production of having Volt-VAR and Volt-Watt active is negligible. This location has a newer underground secondary with larger conductors. The location failed its initial interconnection screen not due to voltage issues but due to distribution transformer loading, which the grid support functions do not address. The lack of major voltage issues makes this location more typical of the distribution secondaries in the pilot study.

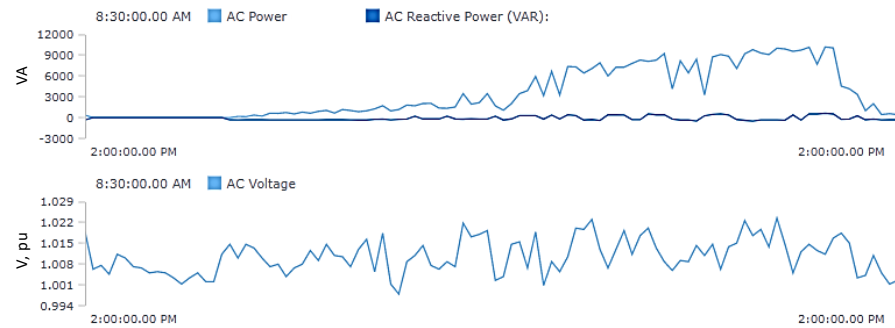

Fig. 13. Inverter PV power dependency on AC voltage showing upper cutoff of the HECO Volt-Watt curve and relationship to DC bus voltage (dot color)

A PV inverter curtails power by taking its maximum power point tracker off the knee point of its present current-voltage (IV) curve and, for the case of the string inverters in this study, the inverter allows the DC bus voltage to rise toward the array open-circuit voltage, Voc. Fig. 14 shows the inverter AC power plotted against the AC terminal voltage with inverter DC bus voltage represented as the color of the dots. Further analysis in future work will show whether curtailed power can be estimated directly from the inverter AC and DC electrical properties without requiring a plane of array irradiance measurement. 


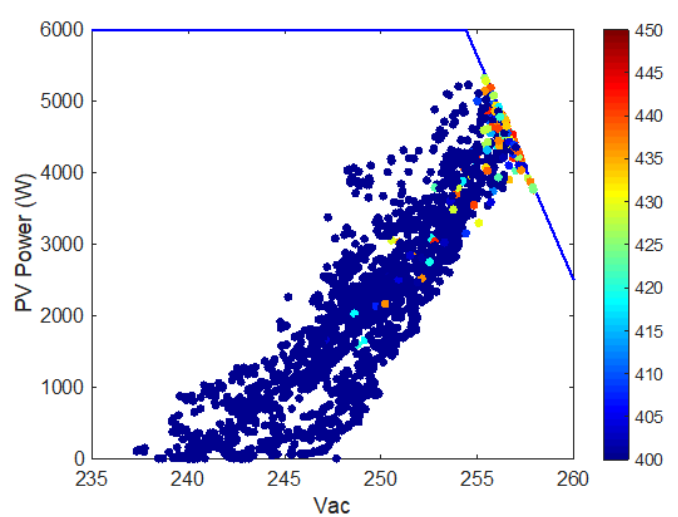

Fig. 14. Inverter PV power dependency on AC voltage showing upper cutoff of the HECO Volt-Watt curve and relationship to DC bus voltage (dot color)

\section{DISCUSSION}

Advanced inverter functions intended to be used for voltage regulation are dependent on the voltage at the inverter terminals. This voltage may be higher behind the customer's meter and is rarely monitored. In this study, behind-the-meter voltage rise was found to be less than $1 \%$ for string inverters and up to $2.5 \%$ for microinverters at full power. Furthermore, at the penetration levels in this study, there was strong dependence of voltage on the PV power production in some locations but minimal dependence in other locations. There was limited measurable effect of Volt-VAR on the PCC voltage for one particular high impedance overhead system due to the prevalence of legacy non-smart inverters and highly resistive secondary on that circuit. However, this is generally expected due to the low $\mathrm{X} / \mathrm{R}$ ratio of many secondary systems. Finally, Volt-Watt curtailment, when it does occur, it can be directly estimated with a POA irradiance measurement. However, further analysis is required to determine if curtailment can be determined using inverter internal electrical measurements.

Some previous work has examined the possibility of undesired dynamic interactions between multiple inverters performing Volt-VAR control at neighboring locations on distribution feeders using computer simulations and in laboratory settings [11], [12]. That work concluded that while adverse inverter-inverter interactions such as oscillations or "hunting" are possible with poorly-selected control parameters, such interactions are unlikely with well-selected Volt-VAR settings. This field study included two clusters of multiple PV systems on the same distribution secondary with highresolution (about $1 \mathrm{~Hz}$ ) sampling of reactive power, voltage, and other parameters, so it afforded an opportunity to observe whether any adverse interactions occurred in the field. No adverse interactions were observed, adding to the growing confidence that autonomous inverter-based grid support functions can be a reliable addition to utility operations.
To date, the findings of this study confirm the results of recent detailed computer simulations of Volt-VAR and VoltWatt on feeders with high levels of distributed PV, which found minimal impact on PV energy production, especially in nearterm scenarios [8]. Despite the pre-selection of customers with expected PV-related secondary problems, evidence of PV curtailment due to Volt-VAR and Volt-Watt is minimal, largely because voltages were rarely high enough for the functions to have a large impact on active power generation. However, additional ongoing work will better quantify these conclusions.

\section{REFERENCES}

[1] "Rule No. 14: Service Connections and Facilities on Customer's Premises.” Hawaiian Electric Company, Inc., 20-Feb-2018.

[2] California Energy Commission, "Rule 21 Smart Inverter Working Group Technical Reference Materials," California Energy Commission, 2014. [Online]. Available:

http://www.energy.ca.gov/electricity_analysis/rule21/. [Accessed: 18-Jun-2014].

[3] "IEEE 1547-2018 - IEEE Standard for Interconnection and Interoperability of Distributed Energy Resources with Associated Electric Power Systems Interfaces," IEEE, Apr. 2018.

[4] A. Nelson et al., "Hawaiian Electric Advanced Inverter Grid Support Function Laboratory Validation and Analysis," National Renewable Energy Lab. (NREL), Golden, CO (United States), NREL/TP-5D00-67485, Dec. 2016.

[5] S. Gonzalez, M. Ropp, A. Fresquez, M. Montoya, and N. Opell, "Multi-PV inverter utility interconnection evaluations," in 2011 37th IEEE Photovoltaic Specialists Conference (PVSC), 2011, pp. 003738-003743.

[6] R. Mahmud, A. Hoke, and D. Narang, "Validating the test procedures described in UL 1741 SA and IEEE P1547.1," in IEEE Photovoltaics Specialists Conference, 2018.

[7] M. Rylander et al., "Methods to determine recommended feeder-wide advanced inverter settings for improving distribution system performance," in 2016 IEEE 43rd Photovoltaic Specialists Conference (PVSC), 2016, pp. 13931398.

[8] J. I. Giraldez Miner et al., "Simulation of Hawaiian Electric Companies Feeder Operations with Advanced Inverters and Analysis of Annual Photovoltaic Energy Curtailment," National Renewable Energy Lab. (NREL), Golden, CO (United States), NREL/TP-5D00-68681, Jul. 2017.

[9] “APS Solar Partner Program: Research Highlights," Electric Power Research Institute (EPRI), 3002009779, Jan. 2017.

[10] F. Bell, A. Nguyen, M. McCarty, K. Atef, and T. Bialek, "Secondary voltage and reactive power support via smart inverters on a high-penetration distributed photovoltaic circuit," in 2016 IEEE Power Energy Society Innovative Smart Grid Technologies Conference (ISGT), 2016, pp. 1-6.

[11] S. Chakraborty, A. Hoke, and B. Lundstrom, "Evaluation of Multiple Inverter Volt-VAR Control Interactions with Realistic Grid Impedances," in IEEE PES General Meeting, 2015.

[12] S. Chakraborty, A. Nelson, and A. Hoke, "Power Hardware-inthe-Loop Testing of Multiple Photovoltaic Inverters' Volt-var Control with Real-time Grid Model," in IEEE Innovative Smart Grid Technologies Conference (ISGT), 2016. 